\title{
Resource unpredictability promotes species diversity and coexistence in an avian scavenger guild: a field experiment
}

\author{
A. Cortés-Avizanda, ${ }^{1,2,5}$ R. Jovani,${ }^{3}$ M. Carrete,,${ }^{1,4}$ and J. A. Donázar ${ }^{1}$ \\ ${ }^{1}$ Department of Conservation Biology, Estación Biológica de Doñana, CSIC, Americo Vespucio s/n, E-41092 Sevilla, Spain \\ ${ }^{2}$ UFZ, Department of Ecological Modelling, Helmholtz Centre for Environmental Research-UFZ, \\ Permoserstrasse 15, 04318 Leipzig, Germany \\ ${ }^{3}$ Department of Evolutionary Ecology, Estación Biológica de Doñana, CSIC, Americo Vespucio s/n, E-41092 Sevilla, Spain \\ ${ }^{4}$ Department of Physical, Chemical and Natural Systems, Universidad Pablo de Olavide, \\ Carretera Utrera km 1, E-41013 Sevilla, Spain
}

\begin{abstract}
Chance per se plays a key role in ecology and evolution, e.g., genetic mutation, resource spatiotemporal unpredictability. In community ecology, chance is recognized as a key factor in community assemblage, but less is known about its role in intraguild processes leading to species coexistence. Here we study the relevance of resource unpredictability per se as a promoter of intraguild positive interspecific interactions and as a biodiversity enhancer in an Old World avian scavenger guild, which has evolved to feed upon spatially and temporally unpredictable resources, i.e., carcasses. We performed a large-scale field experiment in which 58 carcasses were disposed of and observed until complete consumption, either in continuously active supplementary feeding stations (predictable carcasses) or disposed of at random in the field (unpredictable carcasses). Richness of scavenger species was similar at unpredictable and predictable carcasses, but their relative abundances were highly uneven at predictable carcasses leading to higher scavenger diversity (Shannon index) at unpredictable carcasses. Facilitatory interspecific processes only occurred at unpredictable resources but were disrupted in predictable conditions because the dominant specialist species (in our case, the Griffon Vulture Gyps fulvus) arrived earlier and in larger numbers, monopolizing the resource. Small, endangered scavengers congregated at supplementary feeding stations but profited less compared to unpredictable carcasses, suggesting that they could constitute an ecological trap. Our findings offer new insights into the relevance of unpredictability of trophic resources in promoting both positive facilitatory interspecific interactions and species diversity and thus maintaining the function of guilds. Finally, the preservation of randomness in resource availability and the processes associated with its exploitation should be a major goal of conservation strategies aimed to preserve scavenger guilds evolved under naturally unpredictable trophic resources.
\end{abstract}

Key words: assemblage; competition; positive interactions; predictability; spatiotemporal variation; supplementary feeding; vultures.

\section{INTRODUCTION}

Chance shapes ecology and evolution from the minute molecular scale (e.g., random gene mutation) to the ecosystem level (e.g., random-driven community assemblage in oceanic islands [Futuyma 1998]). Ecologists are well aware of the pervasive relevance of chance in any ecological detail (e.g., the movement of an animal causing harm to plants, or a heavy storm lowering reproduction success in a bird colony). However, ecology attempts to make sense of the world by identifying consistent patterns from this underlying randomness. As a result, despite the fact that ecologists understand the pervasiveness of chance, it is inevitably treated as confounding noise, rather than

Manuscript received 8 February 2012; revised 6 June 2012; accepted 7 June 2012. Corresponding Editor: C. C. Wilmers.

${ }^{5}$ E-mail: ainara@ebd.csic.es something worth studying in its own right (but see Hubbell 2001).

Here we focus on the biodiversity consequences of chance when it leads to trophic resource unpredictability (Overington et al. 2008), using the consumption of carcasses by scavengers as our model system. The exploitation of carcasses is thought to be highly dependent on unpredictability because large carcasses are typically unpredictable in time and space leading to long search times (although there are certainly cues and regularities exploited by scavengers when foraging for carcasses that may reduce this unpredictability). However, once found, carcasses provide abundant food. Nonetheless, this event is highly ephemeral. When detected, many scavengers rapidly congregate due to local enhancement and the carcass is quickly consumed (Houston 1979). Indeed, Wilmers et al. (2003) reported a larger diversity of scavenger species at spatiotemporally unpredictable wolf kills than at more aggregated hunter 


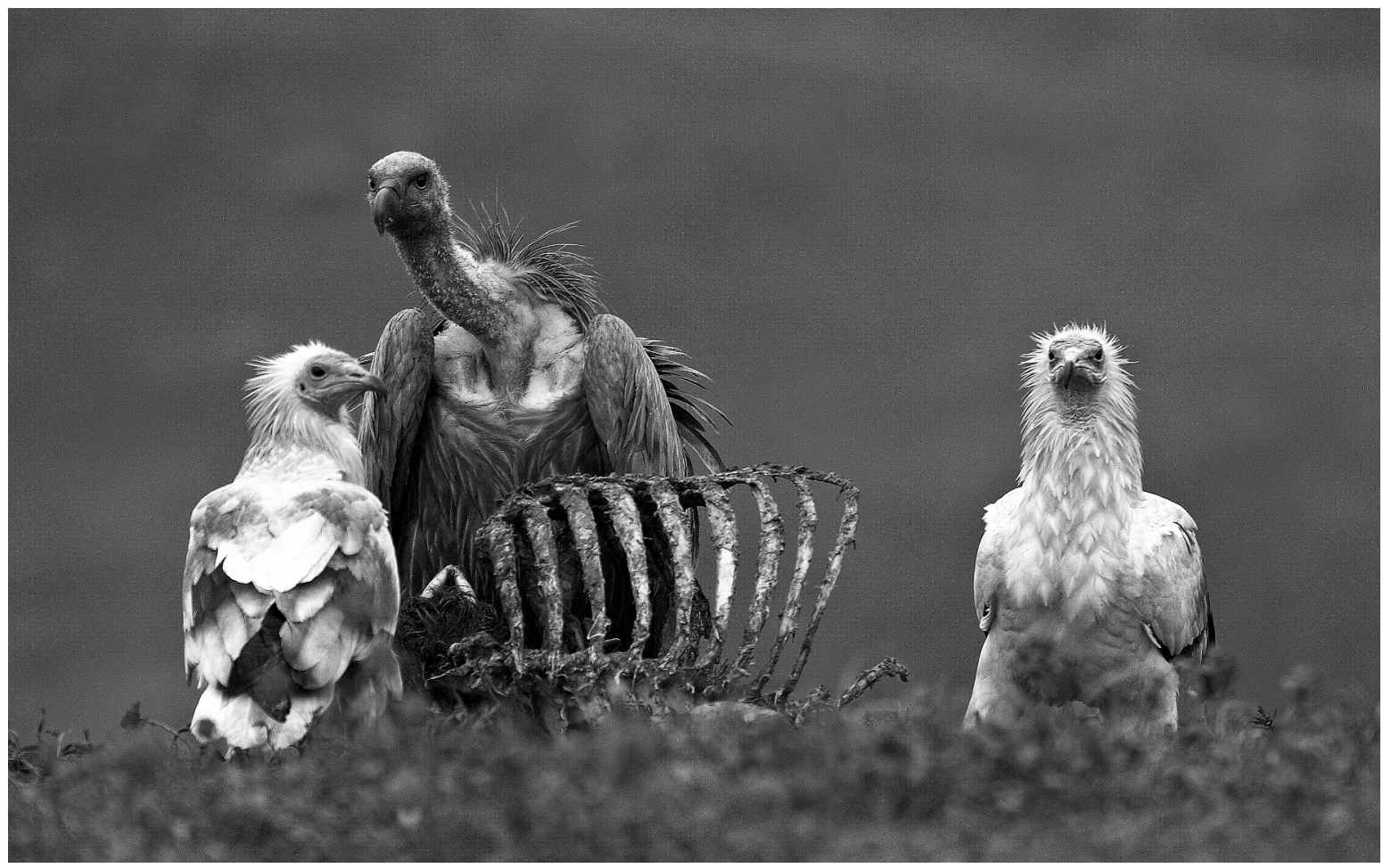

Plate 1. A Griffon Vulture (Gyps fulvus) sharing a carcass with two Egyptian Vultures (Neophron percnopterus). Unpredictable trophic resources allow the occurrence of facilitatory processes promoting the biodiversity and the coexistence of species within an Old World avian scavenger guild. Photo credit: Antonio Atienza.

kills. They suggested this pattern may be attributed to the fact that predictable carcasses are easier to exploit by species with large foraging radii, whereas unpredictable wolf kills are exploited in larger numbers by local dominant species. This result could be seen as an example of the competition-colonization trade-off hypothesis, which has been proposed as a mechanism for explaining species coexistence (Calcagno et al. 2006). Also, Cody (1974:203) suggested that an ephemeral resource, temporarily abundant and relatively unpredictable in space and time, would rule out the possibility of the evolution of displacement patterns among the exploiting species. In this way, the unpredictability and ephemeral nature of these carcasses would enhance the maintenance of biodiversity by relaxing interspecific competition among scavengers either when feeding on a carcass or by favoring the evolution of different speciesspecific strategies.

Moreover, positive interactions between species may also be decisive in diversity and community dynamics (Bruno et al. 2003), being equally probable and important as negative interactions in ecology and evolution (Kikvidze and Callaway 2009). Here we address how resource unpredictability shapes the balance between positive and negative interspecific interactions in an avian scavenger guild, with direct consequences on guild biodiversity. We did so through an experimental approach using an Old World avian scavenger guild as a study system.

In this scavenger guild, species have evolved different behavioral skills and morphology, allowing their coexistence through the sharing of trophic resources (Kruuk 1967, Root 1967, König 1983, Hertel 1994, Hertel and Lehman 1998, Blondel 2003). Some species are specialized carrion consumers (i.e., obligate scavengers, the Gyps vultures) and others are opportunistic-facultative scavengers (Donázar et al. 2010). Facilitatory processes have been proposed to follow two opposite paths within this guild: small-body-sized scavengers landing earlier at carcasses would increase the chances of carcass detection by larger vultures (local enhancement) and large vultures would dismember the carcass (something smaller scavengers cannot do) thus allowing smaller scavengers to profit from the resource (trophic advantage; Kruuk 1967, König 1974, 1983).

Given the particularities of this system, our main hypothesis was that unpredictable trophic resources maintain guild functionality by promoting conditions that favor facilitatory processes (i.e., local enhancement and trophic advantage). To test this hypothesis, we took advantage of a large-scale "natural" experiment that has taken place over the last 40 years in an area of 10000 $\mathrm{km}^{2}$ in northern Spain, which holds one of the largest European populations of avian scavengers (Birdlife International 2004, Cortés-Avizanda et al. 2010; see 
TABLE 1. Abundance of avian scavengers at unpredictable and predictable carcasses.

\begin{tabular}{|c|c|c|c|c|c|c|}
\hline \multirow[b]{2}{*}{ Species } & \multicolumn{3}{|c|}{ Unpredictable } & \multicolumn{3}{|c|}{ Predictable } \\
\hline & Landing & Feeding & Success $\dagger(\%)$ & Landing & Feeding & Success $†(\%)$ \\
\hline Griffon Vulturet & 2540 & & & 9522 & & \\
\hline Egyptian Vulture & 101 & 53 & 52.5 & 197 & 25 & 12.7 \\
\hline Red Kite & 14 & 6 & 42.9 & 26 & 11 & 42.3 \\
\hline Black Kite & 63 & 15 & 23.8 & 4 & 0 & 0.0 \\
\hline Common Raven & 72 & 27 & 37.5 & 28 & 9 & 32.1 \\
\hline Marsh Harrier & 3 & 2 & 66.7 & 0 & 0 & \\
\hline Golden Eagle & 1 & 0 & & 1 & 1 & \\
\hline Species richness, median (range) & $\begin{array}{r}3 \\
(1-5)\end{array}$ & $\begin{array}{c}2 \\
(1-4)\end{array}$ & & $\begin{array}{r}3 \\
(1-4)\end{array}$ & $\begin{array}{c}1 \\
(1-2)\end{array}$ & \\
\hline$H^{\prime}$ median (range) & $\begin{array}{c}0.222 \\
(0.043-1.041)\end{array}$ & $\begin{array}{c}0.171 \\
(0.078-0.857)\end{array}$ & & $\begin{array}{c}0.111^{*} \\
(0.042-0.551)\end{array}$ & $\begin{array}{c}0.000^{* *} \\
(0.022-0.032)\end{array}$ & \\
\hline $\begin{array}{l}H^{\prime} \text { median without Griffon } \\
\text { Vultures (range) }\end{array}$ & $\begin{array}{c}0.562 \\
(0.287-1.386)\end{array}$ & $\begin{array}{c}0.000 \\
(0.377-1.093)\end{array}$ & & $\begin{array}{c}0.470 \\
(0.995-0.314)\end{array}$ & $\begin{array}{c}0.000 \\
(0.451-0.693)\end{array}$ & \\
\hline
\end{tabular}

Notes: Individuals landing and feeding are distinguished. Values for species are numbers of individuals; we also detail the percentage of individuals' successes. Mann Whitney $U$ test compares the median of richness, diversity $\left(H^{\prime}\right)$, as well as number landing.

$\uparrow$ Calculated as the proportion of individuals feeding/landing.

$\$$ Because the activity of Griffons at carcasses was very dynamic and continuously changed (Cortés-Avizanda et al. 2010 ; A. Cortés-Avizanda, R. Jovani, M. Carrete, and J. A. Donázar, unpublished data), we did not calculate the proportion of individuals feeding. In any case, this proportion should be very high ( $\sim 85 \%$ according to authors' unpublished observations on crop sizes).

$* P<0.05 ; * * P<0.001$.

Methods for details). Since the early 1970s, "vulture restaurants" have been used to buffer the decline of extensive livestock (Iribarren 1971, Bijleveld 1974), a trend that has been accentuated since 2001 because of the establishment of new European sanitary regulations (Tella 2001, Deygout et al. 2009, Donázar et al. 2009a, $b$, Cortés-Avizanda et al. 2010). "Vulture restaurants" are selected places in the field in which carcasses are continuously and frequently deposited by local farmers; thus, supplementary feeding stations have changed the spatial-temporal nature of the resource from unpredictable and ephemeral (pulsed) to continuously and predictable. This scenario provides a unique opportunity to examine the prominent role of resource unpredictability in enabling species coexistence. We specifically predict that unpredictable carcasses would show lower levels of resource monopolization by dominant specialist species compared to vulture restaurants, and would allow the occurrence of positive interspecific relationships within the guild (facilitatory processes). As a result, we predict that losing carcass unpredictability would disrupt these interspecific processes, reducing feeding success of subordinate small scavengers and decreasing guild diversity.

\section{Methods}

Field procedures and data collection.-During the three breeding seasons (April-August) of 2004-2006, we monitored scavenger occurrence and feeding success at 58 experimental sheep (Ovis aries) and pig (Sus scrofa) carcasses, the main items consumed by avian scavengers in the study area (Donázar et al. 2010). All of the carcasses used in the experiment were adult animals weighing between 50 and $90 \mathrm{~kg}$; i.e., with sufficiently tough skin to preclude small scavengers from opening the carcass without the mediation of facilitatory processes (by the scavenging activity of Griffon Vultures). Carcasses were disposed (one at a time) in two different ways. Unpredictable carcasses $(N=28)$ were placed in open fields (i.e., fallows or pasturelands) at a minimum distance of $5 \mathrm{~km}$ from the nearest vulture restaurant. In this way, carcasses were unpredictable both in space (open fields are widely distributed in the study area and we selected locations at random within a $10000-\mathrm{km}^{2}$ area) and time (disposal days were spread throughout the breeding season). Predictable carcasses ( $N=30)$ were supplied at supplementary feeding stations. Here, experimental carcasses were monitored when no other carcasses were available, thus avoiding the potential effects linked to variability in the abundance of the trophic resource. All the carcasses were placed at dawn before the start of avian scavenger activity. Carcasses belonging to the two treatments were disposed of in random sequence and one at a time.

Three vulture species breed in the area (the Griffon Vulture Gyps fulvus, the Egyptian Vulture Neophron percnopterus (see Plate 1 for these two), and the Bearded Vulture Gypaetus barbatus), as well as facultative carrion-eaters (Red Kites Milvus milvus, Black Kites Milvus migrans, and Common Ravens Corvus corax). Griffon Vultures, with $\sim 2400$ breeding pairs, outnumber the other taxa, which together come to $<500$ breeding pairs (Cortés-Avizanda et al. 2010).

Bird activity at carcasses was continuously tape recorded by two observers, from the moment of carcass disposal until their complete consumption. Observations were made from a vehicle using binoculars $(10-40 \times)$ and telescopes (20-60×), at a minimum distance of $300 \mathrm{~m}$ to avoid interfering with birds' behavior. The landing of each individual was recorded to the nearest minute. For 
TABLE 2. Comparison of time of arrival, number of birds landing, and time to carcass depletion at unpredictable and predictable carcasses.

\begin{tabular}{|c|c|c|c|c|c|c|}
\hline \multirow[b]{2}{*}{ Metric } & \multicolumn{2}{|c|}{ Predictable } & \multicolumn{2}{|c|}{ Unpredictable } & \multicolumn{2}{|c|}{ Mann-Whitney $U$ test } \\
\hline & Median (range) & $N$ & Median (range) & $N$ & $Z$ & $P$ \\
\hline Time of arrival (min) & $6(0-480)$ & 30 & $60(0-1800)$ & 26 & -4.9 & $<0.001$ \\
\hline Number of birds landed & $293(79-816)$ & 30 & $88(33-252)$ & 27 & -5.6 & $<0.001$ \\
\hline Time to carcass depletion ( $\mathrm{min}$ ) & $166(12-723)$ & 30 & $182(14-932)$ & 25 & 0.0 & 1.000 \\
\hline
\end{tabular}

Note: Sample size $(N)$ varies among different analyses depending on data suitability for each test.

individuals other than Griffon Vultures (hereafter, small scavengers), we recorded whether they fed upon the carcass, and whether this occurred before or after the first Griffon Vulture arrived.

Landing and feeding patterns.-We systematically recorded arrival order and time (in minutes) from carcass disposal until the arrival of the first individual of each observed species. Since individuals sometimes arrived together to a carcass, we considered as a sampling unit the foraging group, defined as one or more individuals of the same species landing within an interval of less than two minutes.

We tested whether Griffon Vultures arrived first to each carcass more/less often than would be expected by chance alone (i.e., considering that all species had the same ability to find the carcasses). To do so, we calculated the proportion of Griffon Vulture groups landing at each carcass (i.e., [number of Griffon Vulture groups]/[total number of groups of any species occurring at a given carcass]). By chance alone, the probability that a group of Griffon Vultures was the first to arrive to a carcass would be equal to this quotient. For instance, if half of the groups landing at a carcass were groups of Griffon Vultures, the probability that Griffons arrived first would be 0.5 . To test this, we ran a linear regression confronting the proportion of Griffon Vulture groups with whether Griffons were (1) or were not (0) the first to arrive at the carcass. We did so separately for predictable and unpredictable carcasses. We then compared the realized slopes of these two regressions with that expected by chance (i.e., slope $=1$ ).

Scavenger intraguild diversity, richness, and facilitatory processes-By means of $t$ tests, we compared scavenger species diversity (Shannon index [Magurran 2003]) and species richness (number of species) between unpredictable and predictable carcasses. To test for the existence of facilitatory processes, we performed three generalized linear mixed models (GLMM; McCullagh and Searle 2000, SAS Institute 2009) with four response variables: (1) whether each individual belonging to a small scavenger species arrived at the carcass before or after the first Griffon Vulture; (2) considering exclusively those small-scavenger individuals landing before Griffon Vultures, whether each individual fed or not; (3) same as response variable 2 , now considering only those smallscavenger individuals landing after Griffon Vultures; and (4) whether those small-scavenger individuals that arrived before Griffon Vultures fed after their arrival. In all four procedures, two categorical explanatory variables were fitted: (1) the type of food resource (i.e., unpredictable or predictable) and (2) the species identity (Egyptian Vulture, Common Raven, Black Kite, or Red Kite). Carcass identity was introduced as a random term to avoid pseudoreplication and to control for spatial and temporal heterogeneity (see Carrete et al. 2010). Binomial error distributions and logit link functions were considered throughout. Models were fitted by using a forward stepwise procedure, which is a well-described procedure for this kind of study system (Carrete et al.

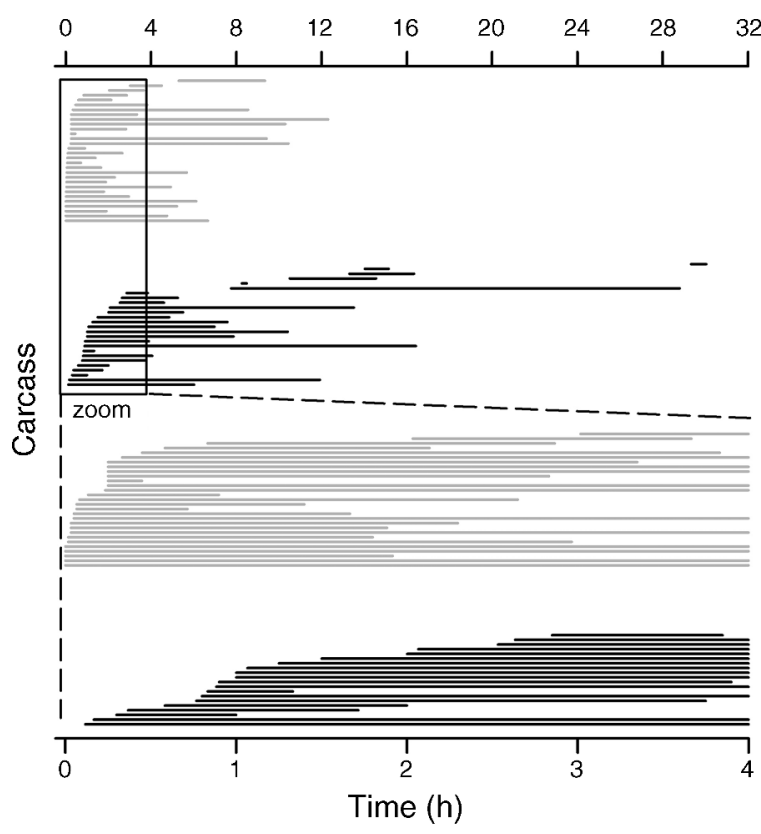

FIG. 1. Temporal dynamics of encountering and consumption of each carcass by scavengers. Time 0 stands for the moment that the carcass was placed in the field. Each carcass is depicted by a line, starting with the arrival of the first scavenger and ending with the total depletion of the resource. Gray lines show predictable carcasses, black lines show unpredictable carcasses. The bottom part of the figure is an expanded view of the first four hours in the top part of the figure. Time until encountering unpredictable carcasses was 35 times more variable than that of predictable carcasses (Levene test, $F_{1,54}$ $=19.805, P<0.001, N$ unpredictable $=26$ carcasses, $N$ predictable $=30$ carcasses), thus supporting its unpredictable nature. Moreover, consumption time was five times more variable for unpredictable carcasses (Levene test, $F_{1,54}=11.259$, $P=0.001 ; N$ unpredictable $=26$ carcasses, $N$ predictable $=30$ carcasses). 


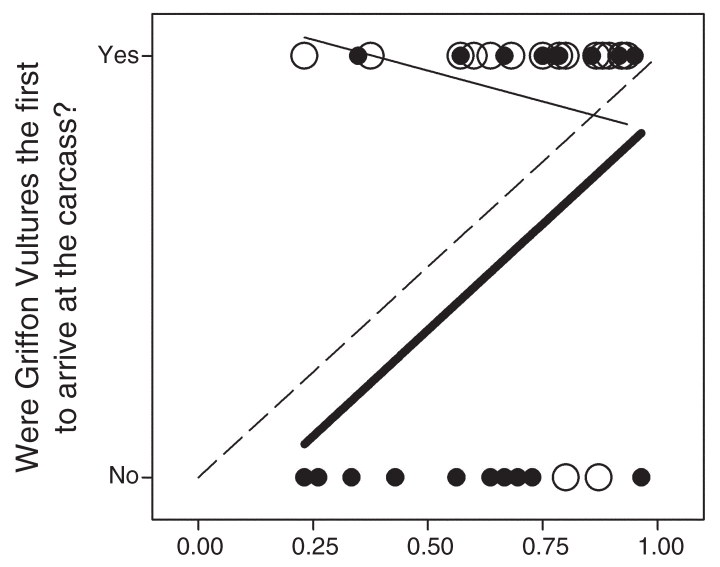

Proportion of groups that were Griffon Vultures

FIG. 2. Diagram showing whether Griffon Vultures were (Yes) or were not (No) the first species arriving at the carcass in relation to the percentage of Griffon Vulture groups observed at each carcass (unpredictable, solid circles; predictable, open circles). The dashed line shows the expected trend if arrivals were completely random. Note that unpredictable carcasses (thick solid line) showed a similar trend to that expected by chance whereas the trend for predictable carcasses (thin solid line) was almost flat, indicating that Griffon Vultures invariably arrived first at carcasses, regardless of their relative abundance.

2010, Cortés-Avizanda et al. 2010). Only significant effects $(P<0.05)$ were retained. Final models were those explaining the highest fraction of the initial deviance.

\section{RESULTS}

Landing and feeding patterns.-We recorded a total of 12572 birds of seven scavenger species at the 58 experimental carcasses. More Griffon and Egyptian Vultures occurred at predictable than at unpredictable carcasses, whereas Black Kites and Common Ravens showed the opposite pattern (Table 1). The time until first arrival was higher at unpredictable carcasses and the median and the maximum number of birds that landed were three times lower than at predictable carcasses (Table 2). Time to carcass depletion was similar between the two carcass treatments (see Table 2 and Fig. 1).

At predictable carcasses, the probability that a group of Griffons was first to land was close to 1 $(100 \%)$, independent of the proportion of groups that were composed of Griffon Vultures $\left(R^{2}=0.03, F_{1,17}=\right.$ $0.547, P=0.469$ ). At unpredictable carcasses, however, the probability that a group of Griffons was first to land increased with the proportion of Griffon Vultures groups recorded at each carcass $\left(R^{2}=0.20\right.$, $\left.F_{1,18}=4.462, P=0.049\right)$ with a slope of $b=1.0063$ $(\mathrm{SE}=0.4764)$, not differing from $1\left(t_{18}=0.0132, P=\right.$ $0.9896)$, i.e., the probability expected by chance alone (Fig. 2).

Unpredictability promotes scavenger guild diversity.Species richness was independent of type of resource.
However, the Shannon diversity index of landing and feeding scavengers was significantly higher at unpredictable carcasses (Table 1). In unpredictable carcasses, Shannon diversity index only showed a mean reduction of 0.01 from the birds that landed to birds that eventually fed on the carcass $\left(t_{27}=2.603, P=0.015\right)$, whereas at predictable resources, this decrease was 11 times higher (mean landing-feeding decrease $=0.11, t_{29}=$ 7.317, $P<0.0001$; Fig. 3). Strikingly, 16 of the 30 predictable carcasses were consumed only by Griffon Vultures, yielding a null diversity index of feeding birds. Discarding Griffon Vultures from analysis, similar results were found, with a mean reduction of the Shannon diversity index of 0.14 at unpredictable carcasses from landing to eventually feeding birds $\left(t_{27}\right.$ $=2.522, P=0.018$ ), and a two-fold decrease at predictable carcasses (mean decrease $=0.30, t_{29}=$ 7.317, $P<0.0001$; Fig. 3).

Unpredictability promotes intraguild processes.-We found that small scavenger species arrived first at $42.9 \%$
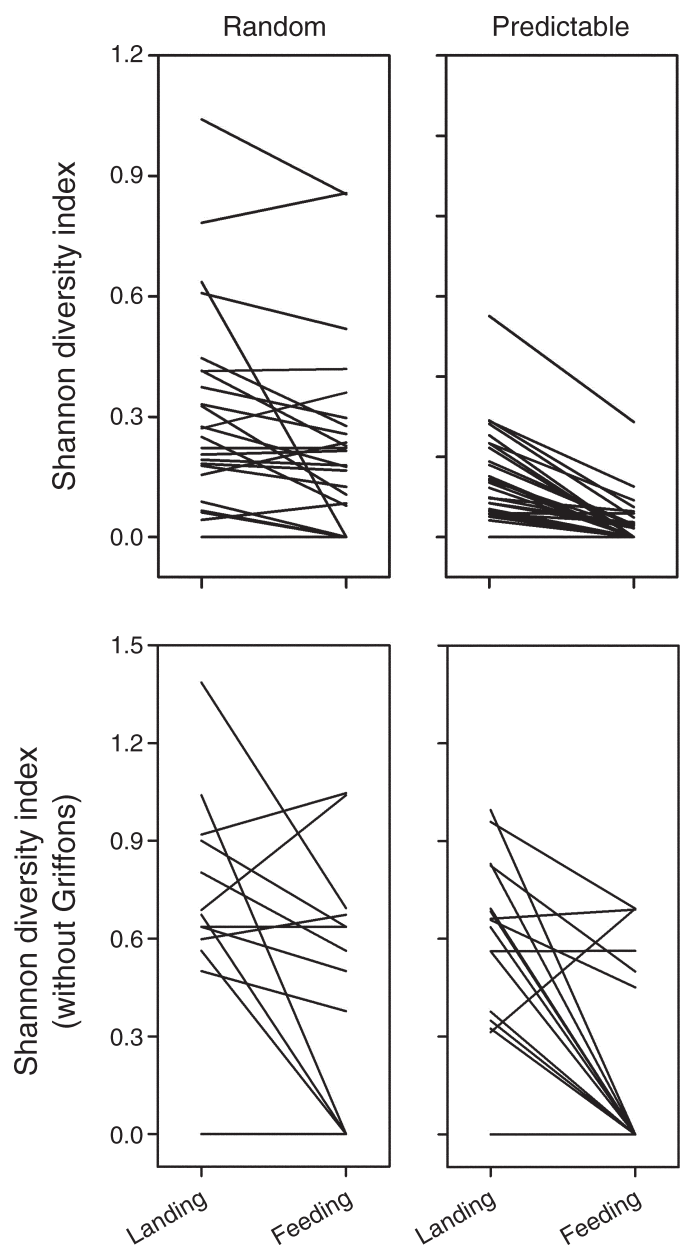

FIG. 3. Changes in the diversity between landing and feeding individuals at unpredictable and predictable carcasses. Diversity was calculated including (upper panels) or excluding (lower panels) Griffon Vultures. 


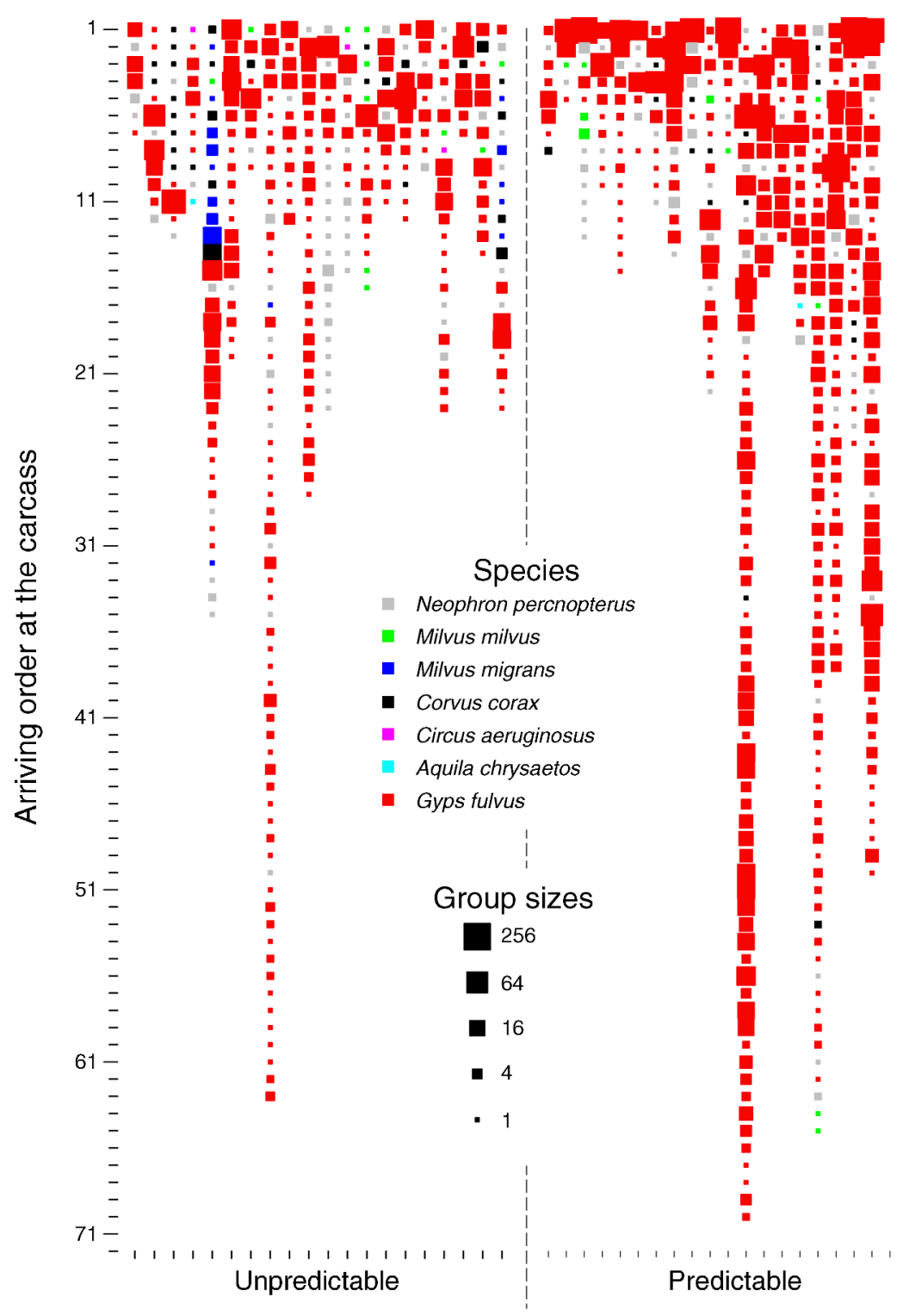

FIG. 4. Arrival order of scavenger species at carcasses $(1=$ first arrival). Each column is a carcass; each square represents the arrival of an individual or group. The size of the square represents group size.

of the unpredictable carcasses, but only at $13.3 \%$ of the predictable ones $\left(\chi^{2}=4.928, P=0.026\right.$; Figs. 2 and 4$)$. In addition, $29 \%$ of the small-scavenger individuals arrived before Griffon Vultures at unpredictable carcasses, but only $6 \%$ did so at predictable carcasses (Figs. 2 and 4). Moreover, the median time taken for Griffons to land at an unpredictable carcass when small scavengers were already present was 31 minutes (range 2-598 minutes, $N$ $=9$ carcasses) whereas the time was double that when no other birds were previously at the carcass (69.5 minutes, range 10-1760 minutes, $N=16$ landings), though this was not statistically significant (Mann-Whitney $U$ test, $Z=-1.444, P=0.152$ ).

At unpredictable carcasses, $42 \%$ of the small scavengers landed before Griffons whereas at predictable carcasses almost all (i.e., 94\%) arrived after Griffons (Fig. 5). $42 \%$ (i.e., $11 \%+31 \%$ landing, respectively, before and after Griffons, see Fig. 5) of the small scavengers fed after the landing of Griffons at unpredictable carcasses whereas at predictable ones only $19 \%$ of them fed (Fig. 5). Interestingly, $11 \%$ of the small scavengers that landed before Griffons at unpredictable carcasses did not feed until the Griffons had opened the carcasses. This kind of facilitation was never observed at predictable carcasses (Fig. 5).

Modeling procedures confirmed that the probability that a small scavenger landed at a carcass earlier than Griffons was higher when the resource was unpredictable, and was species-specific (higher for the two Kite species followed by the Common Raven and the 


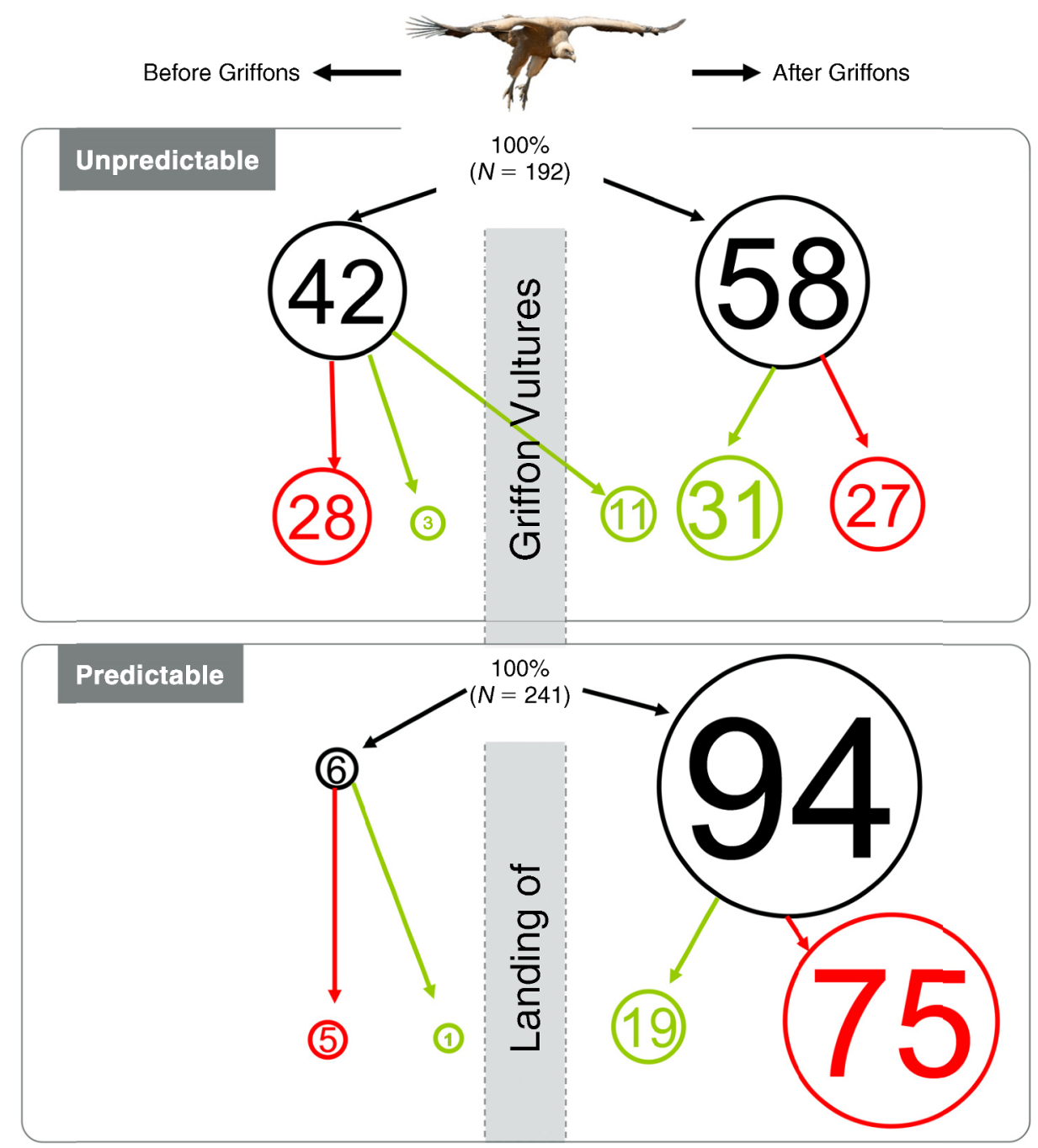

FIG. 5. Schematic representation of the observed changes in the arrival and feeding activity of small scavengers at unpredictable and predictable carcasses in regard to the arrival of Griffon Vultures (vertical gray bar). Numbers represent percentages of individuals arriving (black circles), feeding (green circles), and not feeding (red circles). Note that only at random carcasses did small scavengers profit from the arrival of Griffon Vultures, denoting facilitation. (Photo credit: Antonio Atienza.)

Egyptian Vulture; Table 3). The probability that a small scavenger landed before Griffons fed was independent from resource predictability. Finally, the probability that small scavengers landed after Griffons fed was higher at unpredictable carcasses and was also speciesspecific (Red Kite $>$ Egyptian Vulture $>$ Common Raven $>$ Black Kite).

\section{DisCUSSION}

Our findings reveal that resource unpredictability may be the key mechanism maintaining diversity and governing complex ecological processes, ultimately contributing to intraguild coexistence in the Old World scavenger guild. To date, despite that different research lines have shown evidence of the importance of the effects of stochastic events on community structure (Tilman 1994, Chesson 2000, Hubbell 2001, Harrison et al. 2010), the precise role of randomness per se has rarely been documented (Siepielski et al. 2010). Therefore, knowledge about how the variance in spatial and temporal patterns of trophic resource occurrence shapes species coexistence is key in the comprehension of ecosystem functioning (Begon et al. 2006, Fuhlendorf et al. 2006, Bissonette and Storch 2007). Here we found that species richness was similar at both predictable and unpredictable experimental carcasses but the diversity of avian scavengers was clearly higher when the resource was randomly distributed. The loss of intraguild diversity at predictable resources was not explained by the arrival of a lower number of species but by the larger abundance of the specialist species (Griffon Vultures) whose numbers tripled with respect to random carcasses.

Wilmers et al. (2003) found that more predictable carcasses were consumed by scavengers with higher 
TABLE 3. Effects of type of food and species-specific response on the probability of arrival and feeding of individual small scavengers.

\begin{tabular}{lrrr}
\hline \hline \multicolumn{1}{c}{ Effect } & df & $F$ & $P$ \\
\hline Probability of arriving before Griffon Vultures & & & \\
$\quad$ Food type $\dagger$ & 1,379 & 6.25 & 0.0129 \\
Speciesł & 3,379 & 18.21 & $<0.0001$ \\
Probability of feeding (individuals arriving before Griffon Vultures) & & & \\
$\quad$ Food type & & & n.s. \\
Species & & & n.s. \\
Probability of feeding (individuals arriving after Griffon Vultures) & & & \\
Food type $\dagger$ & 1,285 & 14.81 & 0.0001 \\
Species§ & 3,285 & 3.20 & 0.0237 \\
\hline
\end{tabular}

Notes: The modeling of the probability of feeding distinguishes individuals having arrived before and after Griffon Vultures. The abbreviation n.s. stands for not significant.

$\dagger$ Unpredictable.

\$ From most likely to arrive before Griffon Vultures to least likely: Black Kite > Red Kite > Common Raven > Egyptian Vulture.

$\S$ From most likely to feed to least likely to feed: Red Kite $>$ Egyptian Vulture $>$ Common Raven $>$ Black Kite.

carcass-finding potential (i.e., larger foraging radii), but not necessarily the most competitive species. This is what would be expected under the competititioncolonization trade-off hypothesis (Calcagno et al. 2006). In our study system, the predictability of carcasses at supplementary feeding stations is much higher than that studied by these authors (i.e., hunterderived kills; see Introduction). This much higher predictability has led many Griffons to wait for carcasses at supplementary feeding stations. Interestingly, Griffons are the most competitive and dominant species in the guild. This suggests that the effect of increasing carcass predictability upon guild structure and interspecific processes is not gradual (lineal) but could show thresholds where the function of the guild rapidly shifts.

Unpredictable trophic resources allowed the occurrence of facilitatory processes; both local enhancement and trophic advantage (see Introduction) occurred only at unpredictable carcasses. The facts that there was not a clear order of arrival for the various species at unpredictable carcasses (Fig. 4) and that carcass detection times were reduced by the presence of other scavengers strongly suggests that species used the presence of other individuals of any species to locate carcasses (i.e., local enhancement and not independent discovery). Indeed, for Griffons, the only species with a sufficient sample size to be tested, the time until detection was reduced from 69.5 to 31 minutes when other species where already present at the carcass (although this decrease by local enhancement was not statistically significant). Therefore, we have found that this facilitatory process is more relevant than previously suggested (see Buckley 1996, Jackson et al. 2008; see Introduction), because it is not simply a one-way process from small to large scavengers, but rather all species benefit from one another. Interestingly, however, this did not occur at predictable carcasses where Griffons were already present "waiting for" the new carcasses provided by local farmers at vulture restaurants thus precluding the trophic advantage effect of Griffons toward small scavengers (see Introduction for details). Secondly, carcass unpredictability allowed small scavengers to discover the carcasses earlier than Griffons, which often landed later and in lower numbers allowing small scavengers to feed successfully after the arrival of Griffons, thus enjoying the trophic advantage provided by Griffon Vultures. Interestingly, unpredictable disposed carcasses are the natural condition in which this scavenger assemblage has coevolved to exploit the pulsed carrion resource (Houston 1988, Yang et al. 2008). When the resource becomes predictable at vulture restaurants, specialist dominant scavengers (Griffons) land earlier and in large numbers, often reaching abundances well above the critical threshold $(\sim 200$ individuals) above which smaller species have been found to be systematically excluded from the food resource in the study area (see Cortés-Avizanda et al. 2010).

As biodiversity is accomplished by coexistence of species (Lai and Liu 2005), we thus suggest that facilitatory processes may be behind the high diversity patterns we have reported for randomly disposed carcasses. Pulsed resources, whether in the form of rain for plants in arid environments, mast seeding years for forest rodents, or scattered ephemeral carcasses for scavengers (reviewed in Yang et al. 2008), shape population dynamics and structure of plant and animal communities (Ostfeld and Keesing 2000, Nowlin et al. 2008, Schmidt and Ostfeld 2008, Yang et al. 2008) even governing competition dynamics within guilds (Chesson et al. 2004). In fact, experimental approaches tuning variance in environmental conditions have found striking consequences of variance upon species diversity and carbon cycling in a mesic grassland (Knapp et al. 2002). Within this scenario, we suggest that the 
unpredictability of trophic pulses, in our case ephemeral ungulate carcasses, can be considered necessary to prevent the negative consequences of interspecific competition on biodiversity, which can be compared to the similar effects of homogeneous environments on biodiversity (Hanski 1999).

Conservation implications.-Biodiversity loss is widely recognized as hindering ecosystem functioning worldwide (Schulze and Mooney 1993, Kinzig et al. 2002, Loreau et al. 2002, Naeem and Wright 2003). Supplementary feeding is a common management practice to counteract population decline in vertebrates (Robb et al. 2008). Here we report that small scavenger species were generally more abundant and obtained greater food rewards from unpredictable carcasses (Table 1, Fig. 2). On the contrary, although they occurred in higher numbers at predictable supplies of trophic resources, small scavengers obtained less reward. Thus our study suggests that predictability of trophic resources could act as "ecological traps" (Battin 2004, Gilroy and Sutherland 2007) for less competitive scavengers.

Resource partitioning and facilitatory processes often allow species coexistence and the functioning of ecosystems (reviewed in Blondel 2003). According to our results, preservation of randomness in resource availability and the processes associated with its exploitation should be a major goal of conservation strategies for avian scavengers, and potentially for other guilds evolved under naturally unpredictable food resources. This scenario may be of particular relevance in a world progressively transformed by human activities that modify the availability of trophic resources and/or increase their spatial and temporal predictability (Robb et al. 2008, Donázar et al. 2009a, b, CortésAvizanda et al. 2010). We suggest that relatively smallscale alterations like those resulting from changes in resource distribution may have strong effects on interspecific relationships and guild functioning, also having the potential to trigger consequences for community structure. The paramount relevance of conserving not only single populations and species but also interspecific relationships and ecological processes has recently been stressed (Tylianakis et al. 2010). Therefore, our results suggest that the preservation of spatiotemporal randomness in resource availability should be a priority in conservation strategies aimed to preserve the richness and functionality of guilds evolved under naturally unpredictable trophic resources.

\section{ACKNOWLEDGMENTS}

We are particularly grateful t7o N. Markina, M. Rodriguez, A. Agorreta, D. Campión, M. de la Riva, C. Fernández, M. Razin, and J. I. Deán for their help during fieldwork, data treatment, and analysis. E. Avizanda and I. Afán helped with field data transcriptions. This study was partially funded by Viveros y Repoblaciones de Navarra S.A. (Navarre Government) and the Project CGL2009-12753-C02-01. R. Jovani and M. Carrete were supported by two Ramón y Cajal research contracts from the Ministerio de Ciencia e Innovación (RYC2009-03967 and RYC-2009-04860, respectively).

\section{Literature Cited}

Battin, J. 2004. When good animals love bad habitats: ecological traps and the conservation of animal populations. Conservation Biology 18:1482-1491.

Begon, M., C. R. Townsend, and J. L. Harper. 2006. Ecology: from individuals to ecosystems. Fourth edition. Blackwell Publishing, Malden, Massachusetts, USA.

Bijleveld, M. 1974. Birds of prey in Europe. Macmillan Press, London, UK.

BirdLife International. 2004. Birds in the European Union: a status assessment. BirdLife International, Wageningen, The Netherlands.

Bissonette, J. A., and I. Storch. 2007. Temporal dimensions of landscape ecology: wildlife responses to variable resources. Springer-Verlag, New York, New York, USA.

Blondel, J. 2003. Guilds or functional groups: does it matter? Oikos 100:223-231.

Bruno, J. F., J. J. Stachowicz, and M. D. Bertness. 2003. Inclusion of facilitation into ecological theory. Trends in Ecology and Evolution 18:119-125.

Buckley, N. J. 1996. Food finding and the influence of information, local enhancement, and communal roosting on foraging success of North American vultures. Auk 113:473488 .

Calcagno, V., N. Mouquet, P. Jarne, and P. David. 2006. Coexistence in a metacommunity: the competition-colonization trade-off is not dead. Ecology Letters 9:897-907.

Carrete, M., S. A. Lambertucci, K. Speziale, O. Ceballos, A. Travaini, M. Delibes, F. Hiraldo, and J. A. Donázar. 2010. Winners and losers in human-made habitats: interspecific competition outcomes in two Neotropical vultures. Animal Conservation 13:390-398.

Chesson, P. 2000. Mechanisms of maintenance of species diversity. Annual Review of Ecology and Systematics 31:343-366.

Chesson, P., R. L. E. Gebauer, S. Schwinning, N. Huntly, K. Wiegand, M. S. K. Ernest, A. Sher, A. Novoplansky, and J. F. Weltzin. 2004. Resource pulses, species interactions, and diversity maintenance in arid and semi-arid environments. Oecologia 141:236-253.

Cody, M. L. 1974. Competition and structure of bird communities. Princeton University Press, Princeton, New Jersey, USA.

Cortés-Avizanda, A., J. A. Donázar, and M. Carrete. 2010. Managing supplementary feeding for avian scavengers: guidelines for optimal design using ecological criteria. Biological Conservation 143:1707-1715.

Deygout, C., A. Gault, F. Sarrazin, and C. Bessa-Gomes. 2009. Modeling the impact of feeding stations on vulture scavenging service efficiency. Ecological Modelling 220:1826-1835.

Donázar, J. A., A. Cortés-Avizanda, and M. Carrete. 2010. Dietary shifts in two vultures after the demise of supplementary feeding stations: consequences of the EU sanitary legislation. European Journal of Wildlife Research 56:613621.

Donázar, J. A., A. Margalida, and D. Campión. 2009a. Vultures, feeding stations and sanitary legislation: a conflict and its consequences from the perspective of conservation biology. Sociedad de Ciencias Aranzadi, San Sebastián, Spain.

Donázar, J. A., A. Margalida, M. Carrete, and J. A. SánchezZapata. 2009b. Too sanitary for vultures. Science 326:664.

Fuhlendorf, S. D., W. C. Harrell, D. M. Engle, R. G. Hamilton, C. A. Davis, and D. M. Leslie. 2006. Should heterogeneity be the basis for conservation? Grassland bird response to fire and grazing. Ecological Applications 16:1706-1716.

Futuyma, D. J. 1998. Evolutionary biology. Third edition. Sinauer, Sunderland, Massachusetts, USA.

Gilroy, J. J., and W. J. Sutherland. 2007. Beyond ecological traps: perceptual errors and undervalued resources. Trend in Ecology and Evolution 22:351-356. 
Hanski, I. 1999. Metapopulation ecology. Oxford University Press, Oxford, UK.

Harrison, S., H. Cornell, and K. A. Moore. 2010. Spatial niches and coexistence: testing theory with tarweeds. Ecology 91:2141-2150.

Hertel, F. 1994. Diversity in body size and feeding morphology within past and present vulture assemblages. Ecology 75:1074-1084.

Hertel, F., and N. Lehman. 1998. A randomized nearestneighbor approach for assessment of character displacement: the vulture guild as a model. Journal of Theoretical Biology 190:51-61.

Houston, D. C. 1979. The adaptations of scavengers. Pages 236-286 in A. R. E. Sinclair and M. N. Griffiths, editors. Serengeti: dynamics of an ecosystem. University of Chicago Press, Chicago, Illinois, USA.

Houston, D. C. 1988. Competition for food between neotropical vultures in forest. Ibis 130:402-417.

Hubbell, S. P. 2001. The unified neutral theory of biodiversity and biogeography. Princeton University Press, Princeton, New Jersey, USA.

Iribarren, J. J. 1971. Birds of prey conservation programme in northern Spain. World Wildlife Fund Yearbook 1970-I:4950 .

Jackson, A. L., G. D. Ruxton, and D. C. Houston. 2008. The effect of social facilitation on foraging success in vultures: a modelling study. Biology Letters 4:311-313.

Kikvidze, Z., and R. M. Callaway. 2009. Ecological facilitation may drive major evolutionary transitions. BioScience 59:399-404.

Kinzig, A. P., S. W. Pacala, and D. Tilman. 2002. The functional consequences of biodiversity: empirical progress and theoretical extensions. Princeton University Press, Princeton, New Jersey, USA.

Knapp, A. K., P. A. Fay, J. M. Blair, S. L. Collins, M. D. Smith, J. D. Carlisle, C. W. Harper, B. T. Danner, M. S. Lett, and J. K. McCarron. 2002. Rainfall variability, carbon cycling, and plant species diversity in a mesic grassland. Science 298:2202-2205.

König, C. 1974. Zum verhalten spanischer Geier an Kadavern. Journal für Ornithologie 115:289-320.

König, C. 1983. Interspecific and intraspecific competition for food among Old World vultures. Pages 153-171 in S. R. Wilbur and J. A. Jackson, editors. Vulture biology and management. University of California Press, Berkeley, California, USA.

Kruuk, H. 1967. Competition for food between vultures in east Africa. Ardea 55:171-193.

Lai, Y., and Y. Liu. 2005. Noise promotes species diversity in nature. Physical Review Letters 94:0038102.

Loreau, M., A. Downing, M. Emmerson, A. Gonzalez, J. Hughes, P. Inchausti, J. Joshi, J. Norberg, and O. Sala. 2002. A new look at the relationship between diversity and stability. Pages 79-91 in M. Loreau, S. Naeem, and P.
Inchausti, editors. Biodiversity and ecosystem functioning: synthesis and perspectives. Oxford University Press, Oxford, UK.

Magurran, A. E. 2003. Measuring biological diversity. Blackwell, Oxford, UK.

McCullagh, P., and S. R. Searle. 2000. Generalized linear and mixed models. Wiley-Interscience, New York, New York, USA.

Naeem, S., and J. P. Wright. 2003. Disentangling biodiversity effects on ecosystem functioning: deriving solutions to a seemingly insurmountable problem. Ecology Letters 6:567579 .

Nowlin, W. H., M. J. Vanni, and L. H. Yang. 2008. Comparing resource pulses in aquatic and terrestrial ecosystems. Ecology 89:647-659.

Ostfeld, R. S., and F. Keesing. 2000. Pulsed resources and community dynamics of consumers in terrestrial ecosystems. Trends in Ecology and Evolution 15:232-237.

Overington, S. E., F. Dubois, and L. Lefebvrea. 2008. Food unpredictability drives both generalism and social foraging: a game theoretical model. Behavioral Ecology 19:836-841.

Robb, G. N., R. A. McDonald, D. E. Chamberlain, and S. Bearhop. 2008. Food for thought: supplementary feeding as a driver of ecological change in avian populations. Frontiers in Ecology and Environment 6:476-484.

Root, R. B. 1967. The niche exploitation pattern of the Bluegrey Gnatcatcher. Ecological Monographs 37:317-350.

SAS Institute. 2009. SAS/STAT 9.2. Language reference: Concepts. SAS Institute, Cary, North Carolina, USA.

Schmidt, K. A., and R. S. Ostfeld. 2008. Numerical and behavioral effects within a pulse-driven system: consequences for shared prey. Ecology 89:635-646.

Schulze, E. D., and H. A. Mooney. 1993. Ecosystem function of biodiversity: a summary. Pages 497-510 in E. D. Shulze and H. A. Mooney, editors. Biodiversity and ecosystem function. Springer-Verlag, Berlin, Germany.

Siepielski, A. M., K. L. Hung, E. E. Bein, and M. A. McPeek. 2010. Experimental evidence for neutral community dynamics governing an insect assemblage. Ecology 91:847-857.

Tella, J. L. 2001. Action is needed now, or BSE crisis could wipe out endangered birds of prey. Nature 410:408.

Tilman, D. 1994. Competition and biodiversity in spatially structured habitats. Ecology 75:2-16.

Tylianakis, J. M., E. Laliberté, A. Nielsen, and J. Bascompte. 2010. Conservation of species interaction networks. Biological Conservation 143:2270-2279.

Wilmers, C. C., D. R. Stahler, R. L. Crabtree, D. Smith, and W. M. Getz. 2003. Resource dispersion and consumer dominance: scavenging at wolf and hunter-killed carcasses in Greater Yellowstone, USA. Ecology Letters 6:996-1003.

Yang, L. H., J. L. Bastow, K. O. Spence, and A. N. Wright. 2008. What can we learn from resource pulses? Ecology 89:621-634. 